\begin{tabular}{|l|l|l|l|l|l|} 
J. Tek. Ling & Vol.11 & No.2 & Hal. 157 - 165 & Jakarta, Mei 2010 & ISSN 1441-318X \\
\hline
\end{tabular}

\title{
PENGETAHUAN LOKAL TUMBUHAN OBAT MASYARAKAT DESA DOMPO-DOMPO JAYA, PULAU WAWONII - SULAWESI TENGGARA
}

\author{
Mohammad Fathi Royyani dan Mulyati Rahayu \\ Peneliti di Bidang Botani - Pusat Penelitian Biologi \\ Lembaga Ilmu Pengetahuan Indonesia
}

\begin{abstract}
The ethnobotanical study of plants usage of people in the Wawonii island was conducted in April until May 2006. The local knowledge of medicinal plants in Wawonii island is a result from interaction people of Wawonii island. Environment, another ethnics and globalization, it is as cultured processes. Data were collected on the uses of plants, and more than 62 species of plants were recorded in local names. The data are discussed in the contect of Wawonii island culture, tradition, and way of life. Furthurmore, plants used also show the nearness of emotional relationship between human and environment.
\end{abstract}

Key words: Indigenous knowledge, medicinal plants, Wawonii ethnic, Southeast Sulawesi

\section{PENDAHULUAN}

\subsection{Latar Belakang}

Indonesia merupakan negara kepulauan, terdapat kurang lebih 17.000 pulau yang tersebar di wilayah Indonesia, dari pulau yang berukuran kecil maupun pulau yang berukuran besar. Bentang wilayah yang luas dengan iklim yang hanya mengenal dua musim merupakan keistimewaan tersendiri. Negara ini juga dikenal dengan tingkat keanekaragaman hayati yang tinggi, bahkan tertinggi kedua di dunia setelah Brasil.

Kekayaan Indonesia tidak hanya pada keanekaragam hayati dan nirhayati, tetapi juga memiliki keanekaragamanan tradisi tinggi. Negara ini memiliki 500 entri atau lema. Lema - lema itu sendiri bervariasi dalam kategorikategori: suku bangsa, sub suku bangsa, kelompok sosial yang khas, komunitas yang mendiami suatu pulau kecil, masyarakat terasing dan lain-lain ${ }^{1)}$. Masing-masing lema ini memiliki kearifan lokal dan cara bijak dalam berinteraksi dengan lingkungan, maka berarti pula negara Indonesia memiliki kekayaan kultural. Di antara salah satu kearifan tradisi yang ada adalah pemanfaatan tumbuhan yang digunakan oleh masyarakat sebagai obat untuk menghilangkan berbagai macam penyakit.

Pengetahuan lokal merupakan hasil dari proses belajar berdasarkan persepsi masyarakat sebagai pelaku utama terhadap informasi yang dapat dan dipraktekkan agar sesuai dengan kondisi dimana mereka tinggal. Sehingga pengetahuan lokal mengalami proses dinaminasi yang akan terus berubah seiring dengan perubahan waktu dan makin luas dan beragamnnya interaksi dan informasi yang diperoleh masyarakat.

Pada dasarnya, masyarakat desa Dompo-Dompo Jaya (DDJ) di pulau Wawonii - Sulawesi Tenggara telah memiliki 
pengetahuan lokal mengenai pemanfaatan tumbuhan sebagai obat yang terbentuk secara turun temurun dari nenek moyang mereka dan berkembang seiring dengan berjalannya waktu. Pengetahuan lokal tersebut berupa pengalaman masyarakat dari hasil berinteraksi dengan lingkungannya. Pengetahuan lokal yang dimiliki masyarakat desa DDJ bersifat dinamis, karena dapat dipengaruhi oleh teknologi dan informasi eksternal antara lain kegiatan penelitian para ilmuwan, penyuluhan dari berbagai instansi, pengalaman petani dari wilayah lain, dan berbagai informasi melalui media masa, serta interaksi dengan masyarakat yang lain.

\subsection{Tujuan Penelitian}

Penelitian pengetahuan lokal tentang pemanfaatan tumbuhan sebagai obat tradisional oleh berbagai etnis di pulau Jawa telah cukup banyak dilakukan. Namun, untuk etnis yang menghuni di luar Jawa terutama di pulau Wawoni - Sulawesi Tenggara belum banyak dilakukan, sementara pengetahuan lokal ini terancam oleh arus modernsasi dan globalisasi.

Sehubungan dengan hal tersebut di atas maka dilakukan penelitian etnobotani pemanfaatan keanekaragaman jenis tumbuhan oleh masyarakat lokal Kalisusu. Diharapkan penelitian ini dapat menambah khasanah pengetahuan lokal khususnya tentang tumbuhan obat berbagai etnis di Indonesia.

\section{METODE KERJA}

\subsection{Metode penelitian}

Penelitian ini dilaksanakan di desa Dompo-Dompo Jaya, kecamatan Wawonii Selatan, Kabupaten Konawe - Sulawesi Tenggara pada bulan April - Mei 2006. Dalam pengumpulan data etnobotani digunakan teknik pemilahan informan, yaitu informan kunci (key informan) dan informan biasa. Informan kunci terdiri dari para sando (dukun) dan orang yang dituakan, sedangkan informan biasa adalah masyarakat desa Dompo-dompo Jaya.

Pengamatan dilakukan terhadap pola hidup masyarakat setempat terutama dalam pemanfaatan tumbuhan antara lain sebagai obat tradisional dan konsepsi masyarakat terhadap lingkungan dengan maksud untuk menggali sebanyak mungkin data-data antropologi dan etnobotani.

\subsection{Gambaran Umum Lokasi Penelitian}

Desa Dompo-Dompo Jaya secara administratif merupakan desa baru hasil pemekaran dari desa Roko-Roko pada tahun 1995, namun secara sosio-kultural mereka telah lama bertempat tinggal di daerah tersebut. Desa ini termasuk dalam Kecamatan Wawonii Selatan, Kabupaten Konawe, Sulawesi Tenggara. Mayoritas penduduk desa ini berasal dari Kulisusu kepulauan Buton, sedangkan yang suku asli yaitu Wawonii menjadi minoritas, itupun mereka tidak "asli" lagi karena mereka telah tercampur akibat adanya perkawinan. Dengan kondisi yang demikian bahasa sehari-hari yang digunakan adalah bahasa Kulisusu, bukan bahasa Wawonii.

Menurut data statistik desa tahun 2006, jumlah penduduknya 793 jiwa dengan jumlah KK (Kepala Keluarga) 178. terdiri dari penduduk laki-laki 403 jiwa dan perempuan berjumlah 390 jiwa. Dari jumlah jiwa tersebut yang tercatat sebagai siswa SD (sekolah Dasar) berjumlah 120 anak, SMP 10 anak, dan SMA 6 anak. Tingkat kesadaran pendidikan di desa ini tergolong rendah karena masih kuatnya anggapan kalau sekolah merusak keuangan orang tua.

Untuk mencapai desa ini yang terletak 5 - 100 m dpl menggunakan "kapal cepat"jurusan Lampeapi yang berangkat dari Kendari melewati desa ini setiap 2 hari sekali dengan waktu tempuh 2.5 - 3 jam atau dapat juga menggunakan ferry namun waktu tempuh relatif lebih lama, sekitar 5 sampai 6 jam. 


\section{HASIL DAN PEMBAHASAN}

\subsection{Persebaran Pengetahuan Tumbuhan Obat}

Manusia melakukan interaksi tidak hanya dengan sesama manusia melainkan juga terhadap lingkungan. Berbagai jenis alat yang digunakan sebagai senjata, bangunan rumah, sumber makanan, dan lain-lain merupakan hasil langsung dari interaksi tersebut. Salah satu dari interaksi manusia dengan alam yang akhirnya menjadi pengetahuan adalah tentang pemanfaatan tumbuhan sebagai obat. Dengan demikian, manusia sangat berkepentingan terhadap lingkungan karena tanpa adanya alam yang baik maka ketersediaan manusia untuk kebutuhannya akan berkurang bahkan habis.

Pengetahuan tentang pemanfaatan berbagai jenis tumbuhan untuk kebutuhan hidup manusia, seperti untuk pengobatan, makanan, rumah, alat transportasi, dan juga untuk perdagangan berbeda tiap daerah, walaupun tidak sedikit yang memiliki persamaan. Dengan tingkat keragamanan pengetahuan tentang tumbuhan yang bisa digunakan sebagai obat yang dimiliki Indonesia berarti juga beragam jenis tumbuhan yang dimanfaatkan oleh masyarakat karena setiap daerah memiliki jenis dan cara tersendiri dalam memanfaatkan tumbuhan.

Pada masyarakat desa DDJ yang terletak di kepuauan Wawonii, mereka memiliki pengetahuan tentang pemanfaatan beberapa jenis tetumbuhan sebagai obat dan cara-cara tersendiri dalam memanfaatkannya. Pengetahuan yang ada di desa tersebut diperoleh setidaknya melalui empat cara dan sumber yang berbeda. Ini terjadi seiring dengan perubahan kebudayaan yang ada pada masyarakat desa DDJ.

\section{1) Warisan tradisi}

Masyarakat Kulisusu merupakan salah satu dari sekian banyak suku yang ada di Sulawesi. Sebagaian besar dari mereka hidup di pulau Buton, namun banyak juga yang tinggal di kepualauan lainnya, baik karena menikah dengan suku lain, merantau, atau juga membuka pemukiman baru, seperti yang ada di desa DDJ, kepulauan Wawonii.

Salah satu dari mekanisme kebudayaan adalah pewarisan tradisi yang diturunkan dari generasi ke generasi. Tanpa adanya pewarisan kebudayaan maka satu kebudayaan akan punah. Pengetahuan tumbuhan obat sebagai salah satu bagian dari kebudayaan masyarakat merupakan pengetahuan yang didapat dari proses interaksi manusia dengan lingkungan, baik melalui pengalaman pencobaan atau juga karena mencontoh makhluk hidup yang lain.

Pengetahuan tentang pemanfaatan tumbuhan obat didapat oleh masyarakat desa DDJ dari generasi sebelumnya. Hal ini ditunjukkan ketika wawancara mereka selalu menyarankan agar bertanya pada orang yang lebih tua, karena orang tua lebih banyak pengalaman dan juga banyak mengetahui informasi mengenai tumbuhan yang bisa digunakan sebagai obat. Menurut Alcorn ${ }^{2)}$ pengetahuan tentang pemanfaatan tumbuhan sebagai obat diwariskan dari generasi ke generasi.

\section{2) Interaksi penduduk dengan suku lain}

Pengetahuan tentang tumbuhan obat pada masyarakat di desa DDJ juga berasal dari interaksi mereka dengan suku-suku lain yang ada di sekitarnya. Pola perdagangan sumberdaya alam antar pulau berdampak tidak saja pada peningkatan ekonomi tetapi juga adanya pertukaran pengetahuan. Ketika masyarakat DDJ menjual hasil perkebunannya ke kota Kendari mereka bertemu dengan berbagai suku lain yang ada di kota tersebut, saat itulah terjadi pertukaran ekonomi, informasi, dan juga pengetahuan.

Pola interaksi dengan suku atau 
etnis lain pada kasus DDJ terjadi karena masyarakat yang merantau, seperti yang dialami oleh seorang sando Lasuwu (67 tahun). Beliau dianggap oleh masyarakat desa DDJ dan desa-desa di sekitarnya menguasai banyak ilmu pengobatan tradisional. Menurut pengakuannya, kemampuannnya ini didapat ketika muda saat merantau ke daerah Surabaya (Jawa Timur) pada tahun 1953, dan pada suatu hari ia bertemu dengan seseorang yang mengerti tentang pengobatan tradisional dan khususnya paska bersalin. Tercatat 11 jenis tumbuhan yang digunakan sebagai ramuan obat tradisional, yaitu :

1. kulit kayu mangga "po" Mangifera indica L.

2. kulit kayu kadongdong "kadongdo" Spondias cyatherea Sonnerat

3. kulit kayu kapuk "kawu-kawu" Ceiba pentandra (L.) Gaertner

4. buah jambu perawas "buah malaka" Psidium guajava L.

5. cempaka "jampaka" Michelia champaca L.

6. kulit kayu pulai "kompanga" Alstonia scholaris $\mathrm{R}$. Br.

7. kulit kayu "ciwalase" Pongamia pinnata (L.) Pierre

8. kulit kayu "kosambi" Schleichera oleosa Merr.

9. kulit kayu jeruk bali "lemo" Citrus maxima (Burm.) Merrill

10. Buah pala Myristica fragrans Houtt.

11. buah cengkeh Syzygium aromaticum (L.) Merrill \& Perry

Tidak ada ritual khusus dalam mengambil kulit kayu hanya ketika mengambil kulit pohon pertama (mangga) harus dari bawah ke atas, selanjutnya pada pohon berikutnya bisa dari atas ke bawah, dan diiringi dengan membaca salawat hidup atau cukup dengan ucapan basmallah saja. Pengambilan yang dari bawah ke atas dimaksudkan sebagai perlambang hidup atau pertumbuhan sehingga orang yang meminum ramuan ini akan cepat membaik.

Di samping itu, cara mengambil kulit pohon yang demikian juga menandakan satu prilaku tersendiri dari masyarakat terhadap alam. Mereka menganggap bahwa pohon juga memiliki jiwa yang hidup, perlu dihormati, dan harus ada komunikasi, sehingga cara demikian dianggap sebagai bentuk transformasi jiwa hidup dari pohon ke manusia. Dari jiwa hidup pohon tersebut akan membuat manusia yang memanfaatkannya bisa sembuh.

Pola interaksi yang lain adalah transmigrasi. Di desa ini terdapat orang Jawa, bahkan salah satu diantara mereka menikah dengan penduduk setempat. Orang Jawa ini mengenalkan beberapa jenis tumbuhan yang bisa digunakan sebagai obat, namun sulit mengidentifikasi jenis tumbuhan tersebut karena pengetahuan dari Jawa sudah berbaur dengan pengetahuan setempat.

Interaksi dengan masyarakat lain merupakan proses difusi (peniruan) kebudayaan. Difusi kebudayaan menurut Haviland $^{3)}$ adalah penyebaran adat atau kebiasaan dari kebudayaan yang satu ke kebudayaan yang lain. Bila dikaji lebih lanjut maka wajarlah dugaan yang dilakukan oleh Linton $^{4)}$, menurutnya, sebanyak $90 \%$ dari inti setiap kebudayaan berasal dari peniruan (difusi).

Dalam difusi, masyarakat tidak menyerap semua kebudayaan atau pengetahuan yang masuk melainkan mereka melakukan seleksi terhadap kebudayaan yang masuk untuk disesuaikan dengan kondisi yang ada. Penyerapan pengetahuan yang dilakukan oleh masyarakat desa DDJ membawa keuntungan tersendiri bagi mereka. Karena dengan penyerapan mereka bisa lebih efektif dalam mendayagunakan sumber daya alam yang tersedia untuk kebaikan mereka. Hasil penyerapan pengetahuan tumbuhan obat, membuat mereka kemudian bisa menolong teman, kerabat, dan famili yang menderita karena sakit. 


\section{3) Informasi global}

Masuknya globalisasi tidak selamanya berdampak kurang baik. Di satu sisi fungsi media televisi, koran, radio, atau informasi lainnya yang merupakan bagian dari sistem globalisasi di samping sebagai hiburan juga memberikan informasi yang berguna kepada masyarakat. Sebagai contoh, menurut pengakuan warga, pengetahuan tentang tumbuhan obat, a.l. khasiat buah mengkudu (Morinda citrifolia L.) pada awalnya mereka tidak mengetahui jika buah mengkudu juga berkhasiat obat.

Media turut berperan dalam mempercepat proses persebaran pengetahuan dan akulturasi budaya, dalam hal ini pemanfaatan tumbuhan sebagai obat. Namun, Narajo ${ }^{5)}$ mengemukakan bahwa akulturasi juga dapat menggeser atau bahkan menghilangkan pengetahuan lokal; misalnya seperti yang dialami oleh masyarakat desa DDJ, mereka kini lebih mengenal obat-obat yang tersedia di warung-warung untuk menghilangkan gejala sakit yang dideritanya, terutama generasi muda di desa ini tampaknya telah mengalami degradasi dalam hal pengetahuan tumbuhan berkhasiat obat.

\section{4) Pihak pemerintah}

Pemerintah juga berperan dalam menyebarkan pengetahuan tentang berbagai jenis tumbuhan yang bisa dimanfaatkan sebagai obat. Informasi dari pemerintah ini diperoleh masyarakat melalui komunikasi langsung antara pejabat pemerintah dengan masyarakat. Komunikasi ini terjadi ketika diadakan perlombaan TOGA (Tumbuhan Obat Keluarga).

Berbagai jenis tumbuhan obat yang ditanam di pekarangan, menurut para warga bibitnya diperoleh dari kota Kendari bukan mengambil dari hutan, bahkan ada juga yang berasal dari Jawa. Jenis-jenis tumbuhan yang umum ditanam di pekarangan rumah seperti lengkuas Languas galanga (L.) Stunz, kerokot belanda Portulaca sp., jambu biji Psidium guajava L., keji beling Sericocalyx crispus (L.) Bremek, sereh Cymbopogon citratus (DC.) Stapf, pepaya Carica papaya L., antawali Tinospora crispa (L.) Hook. f. \& Thomson, kelor Moringa pterygosperma Gaertn., sambiloto Andrographis paniculata (Burm. f.) Nees dan lidah mertua Sanseivera sp.

Masyarakat desa DDJ mengenal sebagian dari tumbuhan tersebut antara lain. kelor, keji beling, lidah mertua dan antawali sebagai obat justru ketika ada penggalakan dari pemerintah setempat untuk menanam TOGA. Dari kasus ini kemudian bisa diprediksi bahwa pemerintah turut berperan dalam menyebarkan informasi tentang kegunaan berbagai jenis tumbuhan yang bisa digunakan sebagai obat.

\subsection{Pemanfaatan Tumbuhan Sebagai Obat Tradisional}

Berbagai tatacara pengobatan tradisional merupakan pandangan dan sikap masyarakat pulau Wawonii terhadap tumbuhan. Tumbuhan oleh mereka dipandang tidak saja semata-mata sebagai sesuatu yang bernilai instrumental tetapi jua memiliki roh dan jiwa sehingga perlu perlakuan khusus. Dalam pandangan seperti itu, tumbuhan dengan segala khasiatnya memiliki nilai atau manfaat bukan saja ketika tumbuhan tsb. dapat dimanfaatkan oleh manusia secara langsung.

Dalam pemanfaatan tumbuhan sebagai obat diketahui masyarakat desa Dompo-dompo Jaya menggunakan 62 jenis tumbuhan sebagai obat atas berbagai sakit yang dideritanya, seperti untuk penyakit "berat" (seperti penyakit diabetes yang akut, penyakit dalam dan liver) dan sakit "ringan"(seperti batuk, flu dan gatalgatal), dan untuk perawatan paska bersalin (tabel 1).

Penelitian pemanfaatan tumbuhan sebagai obat tradisional oleh suku Muna di pulau Buton (Sulawesi Tenggara) yang dilakukan oleh Windadri, dkk. ${ }^{6}$ tercatat 61 
jenis, dan penelitian tumbuhan obat yang digunakan masyarakat desa Wawolaa dan Lampeapi yang dilakukan oleh Rahayu, dkk. ${ }^{7)}$ tercatat 73 jenis. Kedua desa ini (Wawolaa dan Lampeapi terletak di pulau Wawonii, dan desa Lampeapi letaknya tidak berjauhan dengan dengan desa Dompo-dompo Jaya. Mayoritas penduduk desa Wawolaa dan Lampeapi adalah suku Wawonii.

Hasil analisa data diketahui 28 jenis tumbuhan (45,16\%) mempunyai manfaatkan yang sama dengan tumbuhan obat yang ditemukan di kedua desa tsb. di atas; dan 9 jenis $(14,52 \%)$ memiliki manfaat yang berbeda; sedangkan 25 jenis $(40,32$ $\%)$ tidak tercantum sebagai bahan obat tradisional(lihat tabel 1).

"Hoinu" Abelmoschus esculentus (L.) Moench atau dikenal dengan nama umum sebagai okra telah cukup lama dibudidayakan di pulau Wawonii. Jenis ini asalnya dari Asia Tenggara ${ }^{8)}$, dan diperkirakan masuk ke pulau Wawonii sekitar 200 tahun yang lalu melalui pulau Buton (Bau-bau) sebagai pintu gerbang perdagangan Indonesia bagian timur. Buah dan daun mudanya di desa Wawolaa dan Lampeapi dimasak sebagai sayuran, bahkan mempunyai arti khusus dalam sistem pertanian tradisional9). Mengingat jenis ini dapat beradaptasi dengan baik di pulau Wawonii, maka dapat dipertimbangkan untuk dikembangkan pada lahan-lahan non produktif yang cukup banyak dijumpai di sekitar desa Dompodompo Jaya.

Delapan jenis tumbuhan yaitu "sirkaya walanda" Annona muricata L., "sirkaya binongko" A. squamosa L., "kapaya" Carica papaya L., "lemo" Citrus maxima (Burm. f.) Merril, "po" Mangifera indica L., "malaka" Psidium guajava L., apokat Persea americana L. dan "tombo" Syzygium aqueum (Burm. f.) Alston merupakan jenis pohon buah-buahan dan 4 jenis di antara tetumbuhan obat tsb. di atas yaitu cengkeh Syzygium aromaticum (L.) Merrill \& Perry, "marica" lada Piper nigrum L., pala Myristica fragrans Houtt. dan "nii" kelapa Cocos nucifera L. merupakan komoditas perdagangan pulau Wawonii. Pohon kelapa bahkan merupakan bagian penting dari tradisi bagi masyarakat pulau Wawonii.

Dalam tradisi masyarak desa Dompodompo Jaya, salah satu prasyarat yang harus dipenuhi oleh pihak pria ketika menyunting wanita adalah kepemilikan pohon kelapa. Masyarakat setempat. memiliki aturan tersendiri dalam menentukan jumlah pohon kelapa yang akan diberikan sebagai mahar atau mas kawin. Untuk menyunting seorang gadis, pohon kelapa sebagai mahar sejumlah 20 pohon, sedangkan untuk menyunting seorang janda hanya diwajibkan $10-15$ pohon, tergantung dari kesepakatan dan kemampuan mempelai pria. Syarat kepemilikan pohon kelapa sebagian dari tradisi perkawinan dimaksudkan bahwa seorang pria memiliki kesiapan materi untuk melaksanakan tanggungjawabnya sebagai kepala keluarga dalam memberikan nafkah bagi keluarganya. Pohon kelapa merupakan yang mempunyai nilai ekonomi sebelum adanya tanaman coklat Theobroma cacao L., "marisa" lada Piper nigrum L. dan "dambo" jambu mete Anacardium occidentale L. Dari nama pulau itu sendiri menunjukkan arti pentingnya pohon kelapa. Dalam bahasa Wawonii kata wawonii berasal dari 2 suku kata yaitu "wawo" berarti daratan dan "nii" artinya kelapa, sehingga secara harfiah wawonii berarti daratan yang dipenuhi atau didominasi dengan pohon kelapa. Saat ini ke 4 jenis tanaman tsb. merupakan komoditi unggulan pulau Wawonii.

Dari hasil wawancara dan pengamatan lapangan diketahui pewarisan pengetahuan tumbuhan obat ke generasi muda dapat dikatakan tidak berlangsung dengan baik. Diduda dengan adanya pelayanan transportasi yang semakin mudah sehingga desa ini semakin terbuka terhadap pendatang merupakan salah satu penyebab terjadinya erosi pengetahuan lokal. Hal ini mendukung pernyataan Waluyo ${ }^{10)}$ yang mengemukakan bahwa modernisasi dengan mudah telah menggeser sejumlah pengetahuan asli suku 
bangsa di luar pulau Jawa. Oleh karena itu perlu digalakkan penyuluhan tentang arti penting pelestarian pengetahuan lokal antara lain pemanfaatan tumbuhan sebagai bahan obat tradisional.

\section{KESIMPULAN}

Pengetahuan lokal yang ada di desa DDJ merupakan hasil dari proses kebudayaan yang panjang, sejalan dengan kehidupan yang dialami oleh mereka. Pengetahuan tentang tumbuhan yang bisa digunakan sebagai obat merupakan bagian dari kebudayaan. Pengetahuan lokal ini tidak ada dengan sendirinya melainkan melalui proses interaksi, difusi kebudayaan, akulturasi, dan penyerapan informasi lainnya. Namun, pengetahuan masyarakat DDJ tentang tumbuhan obat tidak bisa dipilah berdasarkan model interaksinya, hal ini disebabkan proses interaksi yang panjang dan juga pengetahuan tersebut telah melekat dan menjadi bagian yang tidak bisa dipisahkan dari masyarakat.

Tercatat 62 jenis tumbuhan yang digunakan untuk mengobati berbagai penyakit. Beberapa jenis diantaranya memunyai nilai tambah seperti sebagai komoditas perdagangan, tanaman pangan dan buah-buahan.

\section{DAFTAR PUSTAKA}

1. Melalatoa, J.M. 1995. Ensiklopedi Suku Bangsa Di Indonesia. Departemen Pendidikan dan Kebudayaan RI.

2. Alcom, J.B. 1995. The Scope and Aims of Ethnobotany In A Developing Word. in: Evans, R. \& S. Von Reis (eds.) Ethnobotany: Evolution of A Dicipline. Oregon Dioscorides Press.

3. Haviland, W.A. 1993. Antropologi. Jilid 2 Jakarta Erlangga.

4. Linton, R. 1940. The Study of Man. New York Appleton

5. Narajo, P., 1995. The Urgent Need for The Study of Medicinal Plants. in: Evans, R. \& S. Von Reis (eds.). Ethnobotany: Evolution of A Dicipline. Oregon Dioscorides Press.

6. Windadri, F.I., M. Rahayu, T. Uji dan H. Rustiami. 2006. Pemanfaatan Tumbuhan Sebagai Bahan Obat Oleh Masyarakat Lokal Suku Muna Di Kecamatan Wakarumba, Kabupaten Muna, Sulawesi Tenggara. Biodiversitas 7 (4) : 333 - 339.

7. Rahayu, M., S. Sunarti, D. Sulistiarini dan S. Prawiroatmodjo. 2006. Pemanfaatan Tumbuhan Obat Secara Tradisional Oleh Masyarakat Lokal Di Pulau Wawonii, Sulawesi Tenggara. Biodiversitas 7 (3): 245 - 250.

8. Siesmonsma, J.S. 1994. Abelmoschus esculenthus (L.) Moench. in :Siesmonsma, J.S. \& K. Piluek (eds.) Plant Resourches of South-East Asia No. 8 Vegetable. Bogor PROSEA

9. Rahayu, M. dan D. Sulistiarini. 2008. Etnobotani "Hoinu" Abelmoschus esculentus (L.) Moench: Pemanfaatan, Prospek dan Pengembangannya Di Sulawesi Tenggara. Jurnal Teknologi Lingkungan 9 (1) : $79-84$.

10. Waluyo, E.B. 1991. Perkembangan Pemanfaatan Tumbuhan Obat di luar Pulau Jawa. Prosiding Pemanfaatan Tumbuhan Obat Dari Hutan Tropika Indonesia. IPB Bogor, 15 Mei 1991. 
Tabel 1. Jenis-jenis Tumbuhan Obat Di Desa Dompo-dompo Jaya, Pulau Wawonii Sulawesi Tenggara

\begin{tabular}{|c|c|c|c|c|c|}
\hline No & Nama IImiah & $\begin{array}{l}\text { Nama } \\
\text { Lokal }\end{array}$ & $\begin{array}{l}\text { Bag. Yg. } \\
\text { Digunakan }\end{array}$ & Cara Penggunaan & Kegunaan \\
\hline 1 & $\begin{array}{l}\text { Abelmoschus esculenthus } \\
\text { (L.) Moench* }\end{array}$ & Hoinu & Daun & $\begin{array}{l}\text { Ditumbuk, ditapel ke dahi } \\
\text { atau vagina }\end{array}$ & $\begin{array}{l}\text { Obat demam, } \\
\text { paska persalinan }\end{array}$ \\
\hline 2 & Acorus calamus L.* & Daria & Rimpang & Ditumbuk, ditapel & Penurun panas \\
\hline 3 & Adenanthera pavonina L. & Dampi & Daun & Dikunyah-kunyah & Obat sariawan \\
\hline 4 & Ageratum conyzoides L.* & $\begin{array}{l}\text { Sampah } \\
\text { walu }\end{array}$ & Daun & $\begin{array}{l}\text { Diremas, airnya } \\
\text { dibalurkan / diminum }\end{array}$ & Antiseptik \\
\hline 5 & $\begin{array}{l}\text { Alstonia scholaris (L.) R. } \\
\text { Br.* }^{*}\end{array}$ & Kompanga & Kulit batang & Direbus, airnya diminum & $\begin{array}{l}\text { Obat malaria, } \\
\text { demam }\end{array}$ \\
\hline 6 & Annona muricata L. & $\begin{array}{l}\text { Sirkaya } \\
\text { walanda }\end{array}$ & Daun & $\begin{array}{l}\text { Direbus dgn. Daun kelor, } \\
\text { diminum }\end{array}$ & Obat sakit kepala \\
\hline 7 & Annona squamosa L. & $\begin{array}{l}\text { Sirkaya } \\
\text { binongko }\end{array}$ & Daun & $\begin{array}{l}\text { Dremas, digosok ke } \\
\text { kepala }\end{array}$ & Obat sakit kepala \\
\hline 8 & Areca catechu L.* & Wua & Buah muda & Direbus, airnya diminum & obat diabetes \\
\hline 9 & $\begin{array}{l}\text { Bambusa vulgaris } \\
\text { Schrader* }\end{array}$ & Bambu & Batangnya & $\begin{array}{l}\text { Diparut, disaring, airnya } \\
\text { diminum }\end{array}$ & Diabetes \\
\hline 10 & $\begin{array}{l}\text { Barringtonia racemosa } \\
\text { (L.) Spreng.** }\end{array}$ & Kambahu & Daun & $\begin{array}{l}\text { Direbus dgn. ramuan } \\
\text { lainnya, diminum }\end{array}$ & Obat berak darah \\
\hline 11 & $\begin{array}{l}\text { Blumea balsamifera (L.) } \\
\text { DC.** }\end{array}$ & Oombu & Daun muda & $\begin{array}{l}\text { Ditumbuk, airnya } \\
\text { diminum }\end{array}$ & $\begin{array}{l}\text { Obat demam, } \\
\text { sakit kuning }\end{array}$ \\
\hline 12 & $\begin{array}{l}\text { Calophyllum inophyllum } \\
\text { L.* }\end{array}$ & Donggala & Getah daun & $\begin{array}{l}\text { Diteteskan ke bagian } \\
\text { yang sakit }\end{array}$ & Obat tetes mata \\
\hline 13 & Canavalia sp. & $\begin{array}{l}\text { Laue-laue } \\
\text { tahi }\end{array}$ & Daun & $\begin{array}{l}\text { Dilayukan di atas api, } \\
\text { ditapel }\end{array}$ & Obat bisul \\
\hline 14 & Carica papaya L.* & Kapaya & $\begin{array}{l}\text { Akar dan daun } \\
\text { tua }\end{array}$ & Direbus, airnya diminum & $\begin{array}{l}\text { Obat malaria, } \\
\text { demam, peny. } \\
\text { dalam }\end{array}$ \\
\hline 15 & $\begin{array}{l}\text { Ceiba pentandra (L.) } \\
\text { Gaertner* }\end{array}$ & Kawu-kawu & Daun & $\begin{array}{l}\text { Ditumbus, airnya } \\
\text { diminum }\end{array}$ & $\begin{array}{l}\text { Obat demam, } \\
\text { peny. dalam }\end{array}$ \\
\hline 16 & $\begin{array}{l}\text { Citrus maxima (Burm.) } \\
\text { Merrill }\end{array}$ & Lemo & $\begin{array}{l}\text { Buah, kult btg \& } \\
\text { daun }\end{array}$ & $\begin{array}{l}\text { Diperas dengan ramuan } \\
\text { lainnya }\end{array}$ & $\begin{array}{l}\text { Obat batuk, } \\
\text { peny. dalam }\end{array}$ \\
\hline 17 & Clerodendron sp. & $\begin{array}{l}\text { Kandi-kandi } \\
\text { meo }\end{array}$ & daun. & $\begin{array}{l}\text { Diremas, dioleskan ke } \\
\text { bag. yg. sakit }\end{array}$ & $\begin{array}{l}\text { Obat eksim \& } \\
\text { gatal-gatal }\end{array}$ \\
\hline 18 & Cocos nucifera L. & Nii & Tangkai buah & Direbus, airnya diminum & $\begin{array}{l}\text { Obat batuk, } \\
\text { peny. dalam }\end{array}$ \\
\hline 19 & Crescentia cujete L.* & Taku & Kulit kayu & Direbus, airnya diminum & obat diabetes \\
\hline 20 & Crinum asiaticum L.* & Kapupu & Umbi & $\begin{array}{l}\text { Dibakar, ditapel ke } \\
\text { vagina }\end{array}$ & $\begin{array}{l}\text { Perawatan paska } \\
\text { persalinan }\end{array}$ \\
\hline 21 & Crotalaria incana L.** & Dara-dara & Buah dan daun & $\begin{array}{l}\text { Ditumbuk dgn lada, } \\
\text { airnya diminum }\end{array}$ & Paska persalinan \\
\hline 22 & Cucurbita sp. & Tambuloko & Buah & ditapelkan ke lidah & $\begin{array}{l}\text { obat sariawan } \\
\text { pada anak-anak }\end{array}$ \\
\hline 23 & Curcuma longa L.** & \begin{tabular}{|l|} 
Kundaro \\
muhalo
\end{tabular} & Rimpang & Diparut, airnya diminum & Obat luka dalam \\
\hline 24 & $\begin{array}{l}\text { Dendrophthoe pentandra } \\
\text { (L.) Miq.** }\end{array}$ & $\begin{array}{l}\text { Susuan } \\
\text { tomi }\end{array}$ & Daun & Direbus, airnya diminum & $\begin{array}{l}\text { Obat penyakit } \\
\text { dalam }\end{array}$ \\
\hline 25 & Dischidia sp.* & Apa-apa & Daun & Direbus, airnya diminum & Obat sesak nafas \\
\hline
\end{tabular}




\begin{tabular}{|c|c|c|c|c|c|}
\hline No & Nama IImiah & Nama Lokal & $\begin{array}{c}\text { Bag. Yg. } \\
\text { Digunakan }\end{array}$ & Cara Penggunaan & Kegunaan \\
\hline 26 & Elephantopus scaber $\mathrm{L}^{*}$ & Kateba & Daun & Direbus, airnya diminum & $\begin{array}{l}\text { Perawatan paska } \\
\text { persalinan }\end{array}$ \\
\hline 27 & Embelia ribes Burm.f. ${ }^{* *}$ & Belailaro & Daun & Direbus, airnya diminum & Obat bersalin \\
\hline 28 & Euphorbia sp. & $\begin{array}{l}\text { Tagundu- } \\
\text { gundu }\end{array}$ & Seluruh bagian & Direbus, airnya diminum & obat asma \\
\hline 29 & $\begin{array}{l}\text { Gmelina elliptica J.E. } \\
\text { Smith* }\end{array}$ & Tara & Daun & Direbus, airnya diminum & Obat cacing \\
\hline 30 & $\begin{array}{l}\text { Helminthostachys } \\
\text { zeylanica (L.)Hook.* }\end{array}$ & Panamoloku & Akar & Direbus, diminum & Obat sakit kuning \\
\hline 31 & Hibiscus tiliaceus L. ** & Boncu & Batangnya & Direbus, airnya diminum & Obat tetes mata \\
\hline 32 & Hyptis brevipes Poit* & Kapopodi & Daun & Direbus, airnya diminum & $\begin{array}{l}\text { Obat penyakit } \\
\text { dalam }\end{array}$ \\
\hline 33 & Ipomoea sp. & $\begin{array}{l}\text { Ntanga- } \\
\text { ntanga }\end{array}$ & Daun & $\begin{array}{l}\text { Diremas-remas, ditapel } \\
\text { ke dahi }\end{array}$ & $\begin{array}{l}\text { Obat demam, } \\
\text { peny. dalam }\end{array}$ \\
\hline 34 & Jatropha multifida L.* & Dium & Getah & $\begin{array}{l}\text { Diteteskan ke bagian } \\
\text { yang sakit }\end{array}$ & Penutup luka \\
\hline 35 & $\begin{array}{l}\text { Kalanchoe pinnata (Lamk) } \\
\text { Pers. }\end{array}$ & Cakar bebek & Daun & Diremas, tapel ke kepala & Obat sakit kepala \\
\hline 36 & $\begin{array}{l}\text { Languas galanga (L.) } \\
\text { Stunz* }\end{array}$ & Laja & Rimpang & $\begin{array}{l}\text { Digosok-gosok ke bag. } \\
\text { yg. sakit }\end{array}$ & Obat sakit kulit \\
\hline 37 & $\begin{array}{l}\begin{array}{l}\text { Lannea coromandelica } \\
\text { (Houtt.) Merr.* }\end{array} \\
\end{array}$ & Kayu jawa & Kulit kayu & Dipanaskan, dibalutkan & Penutup luka \\
\hline 38 & Mangifera indica L. & Po & Kulit batang & $\begin{array}{l}\text { Direbus dgn. ramuan } \\
\text { lainnya, diminum }\end{array}$ & $\begin{array}{l}\text { Obat penyakit } \\
\text { dalam }\end{array}$ \\
\hline 39 & $\begin{array}{l}\text { Manih ot esculenta } \\
\text { Crantz* }^{*}\end{array}$ & Pasikela keu & Daun & $\begin{array}{l}\text { Diremas, dioleskan ke } \\
\text { bag.yg. Sakit }\end{array}$ & Obat sakit kulit \\
\hline 40 & Michelia champaca L. & Jambaka & getah & $\begin{array}{l}\text { Diteteskan ke bagian } \\
\text { yang sakit }\end{array}$ & Obat sakit gigi \\
\hline 41 & Morinda citrifolia L. & Kamba & Buah dan daun & Direbus, airnya diminum & $\begin{array}{l}\text { Obat penyakit } \\
\text { dalam }\end{array}$ \\
\hline 42 & Myristica fragrans Houtt. & Pala & Buah & $\begin{array}{l}\text { Direbus dgn ramuan } \\
\text { lainnya, diminum } \\
\end{array}$ & $\begin{array}{l}\text { Obat penyakit } \\
\text { dalam }\end{array}$ \\
\hline 43 & Persea americana Mill * & Apokat & Daun & Direbus, airnya diminum & Obat darah tinggi \\
\hline 44 & Phyllanthus niruri L. & $\begin{array}{l}\text { Kaninii } \\
\text { nopuru }\end{array}$ & Daun & Dikunyah-kunyah & $\begin{array}{l}\text { Obat penyakit } \\
\text { dalam }\end{array}$ \\
\hline 45 & Piper betle L.* & Lewe sena & Daun, buah & $\begin{array}{l}\text { Direbus, airnya diminum } \\
\text { atau dikunyah }\end{array}$ & $\begin{array}{l}\text { perawatan paska } \\
\text { persalinan }\end{array}$ \\
\hline 46 & Piper nigrum L.* & Marica & Buah & $\begin{array}{l}\text { Ditumbuk, campur air, } \\
\text { diminum }\end{array}$ & $\begin{array}{l}\text { Perawatan paska } \\
\text { persalinan }\end{array}$ \\
\hline 47 & Polygala paniculata L. & Hakawo & Akar & $\begin{array}{l}\text { Dicampur dengan } \\
\text { minyak, dibalurkan }\end{array}$ & Obat pegal linu \\
\hline 48 & \begin{tabular}{|l} 
Pongamia pinnata (L.) \\
Pierre
\end{tabular} & Ciwalase & akar & Direbus, airnya diminum & Obat sakit gigi \\
\hline 49 & Psidium guajava L. ${ }^{*}$ & Malaka & Daun & Direbus, airnya diminum & Obat berak darah \\
\hline 50 & $\begin{array}{l}\text { Scaevola taccada } \\
\text { (Gaertn.) Roxb.* }\end{array}$ & Bonculo & Daun & $\begin{array}{l}\text { Diremas-remas, airnya } \\
\text { diminum }\end{array}$ & $\begin{array}{l}\text { Obat malaria, } \\
\text { pegal linu }\end{array}$ \\
\hline 51 & Schleichera oleosa Merr. & Kosambi & Kulit batang & Direbus, diminum & $\begin{array}{l}\text { Obat penyakit } \\
\text { dalam }\end{array}$ \\
\hline
\end{tabular}




\begin{tabular}{|c|c|c|c|c|c|}
\hline No & Nama IImiah & $\begin{array}{l}\text { Nama } \\
\text { Lokal }\end{array}$ & $\begin{array}{c}\text { Bag. Yg. } \\
\text { Digunakan }\end{array}$ & Cara Penggunaan & Kegunaan \\
\hline 52 & $\begin{array}{l}\text { Sesbania grandiflora (L.) } \\
\text { Pers. }{ }^{* *}\end{array}$ & \begin{tabular}{|l|} 
Kamba \\
dawa
\end{tabular} & Daun & $\begin{array}{l}\text { Ditumbuk dgn tepung } \\
\text { beras, dibalur }\end{array}$ & $\begin{array}{l}\text { Perawatan bayi } \\
\text { agar sehat }\end{array}$ \\
\hline 53 & Spiranthes sp. & Riung sula & Daun & Direbus, airnya diminum & Obat mencret \\
\hline 54 & $\begin{array}{l}\text { Spondias cyatherea } \\
\text { Sonnerat }\end{array}$ & Kadongdo & kulit batang & $\begin{array}{l}\text { Direbus dgn ramuan } \\
\text { lainnya, diminum }\end{array}$ & $\begin{array}{l}\text { Obat penyakit } \\
\text { dalam }\end{array}$ \\
\hline 55 & Strobilanthes sp. ${ }^{* *}$ & Umpuia & Daun & Direbus, airnya diminum & $\begin{array}{l}\text { Perawatan paska } \\
\text { persalinan }\end{array}$ \\
\hline 56 & $\begin{array}{l}\text { Syzygium aqueum } \\
\text { (Burm.f.) Alston }\end{array}$ & Tombo & Daun muda & Dikunyah-kunyah & $\begin{array}{l}\text { Obat batuk, } \\
\text { peny. dalam }\end{array}$ \\
\hline 57 & $\begin{array}{l}\text { Syzygium aromaticum (L.) } \\
\text { Merrill \& Perry }\end{array}$ & Cengkeh & Kulit batang & $\begin{array}{l}\text { Direbus dgn ramuan } \\
\text { lainnya, diminum }\end{array}$ & $\begin{array}{l}\text { Obat penyakit } \\
\text { dalam }\end{array}$ \\
\hline 58 & Terminalia catappa L. ${ }^{*}$ & Tolike & Akar & Direbus, airnya diminum & penawar racun \\
\hline 59 & Wedelia biflora (L.) DC. ${ }^{*}$ & $\begin{array}{l}\begin{array}{l}\text { Komba- } \\
\text { komba }\end{array} \\
\end{array}$ & Daun & Direbus, airnya diminum & $\begin{array}{l}\text { Perawatan paska } \\
\text { persalinan }\end{array}$ \\
\hline 60 & $\begin{array}{l}\text { Zingiber purpureum } \\
\text { Roxb.* }\end{array}$ & Bangule & Rimpang & Ditumbuk, ditapel & Obat kulit \\
\hline 61 & $?$ & $\begin{array}{l}\text { Dampe- } \\
\text { dampe watu }\end{array}$ & Daun & $\begin{array}{l}\text { Direbus, airnya diminum } \\
\text { atau disayur }\end{array}$ & $\begin{array}{l}\text { Obat ambien, } \\
\text { susah buang } \\
\text { besar }\end{array}$ \\
\hline 62 & $?$ & \begin{tabular}{|l|} 
Oloso \\
karambau
\end{tabular} & Daun & Direbus, airnya diminum & $\begin{array}{l}\text { Obat penyakit } \\
\text { dalam }\end{array}$ \\
\hline
\end{tabular}

Keterangan * = Jenis tumbuhan obat yang pemanfaatannya sama

** $=$ Jenis tumbuhan obat yang pemanfaatannya berbed 